\title{
Adaptabilidade, estabilidade e resistência a patógenos em genótipos de feijoeiro
}

\author{
Cleber Vinicius Giaretta Azevedo(1), Tamires Ribeiro(1), Daiana Alves da Silva(1), \\ Sérgio Augusto Morais Carbonell ${ }^{(1)}$ e Alisson Fernando Chiorato ${ }^{(1)}$
}

${ }^{(1) I n s t i t u t o A g r o n o ̂ m i c o, ~ C e n t r o ~ d e ~ G r a ̃ o s ~ e ~ F i b r a s, ~ F a z e n d a ~ S a n t a ~ E l i s a, ~ C E P ~ 13001-970 ~ C a m p i n a s, ~ S P, ~ B r a s i l . ~ E-m a i l: ~ c v g . a z e v e d o @ g m a i l . c o m, ~}$
tamires_r1@yahoo.com.br, daiagrouel2002@hotmail.com, carbonel@iac.sp.gov.br, afchiorato@iac.sp.gov.br

Resumo - O objetivo deste trabalho foi avaliar a resistência de genótipos de feijoeiro aos principais patógenos da cultura, bem como a adaptabilidade e a estabilidade de produção de grãos desses genótipos. Avaliaram-se 26 genótipos de feijoeiro quanto à resistência a Colletotrichum lindemuthianum, Fusarium oxysporum f. sp. phaseoli e Xanthomonas axonopodis pv. phaseoli, por meio de inoculação, em laboratório, e em 19 ensaios de valor de cultivo e uso (VCU), em diferentes locais do Estado de São Paulo, nas safras das "águas", "seca” e "inverno", durante os anos agrícolas 2011, 2012 e 2013. Dezoito genótipos foram considerados resistentes: sete deles a $C$. lindemuthianum, sete a $F$. oxysporum f. sp. phaseoli e quatro a $X$. axonopodis pv. phaseoli. A reação de resistência aos patógenos está associada à estabilidade dos genótipos. Por meio das análises GGE biplot, foi possível identificar genótipos com adaptabilidade e estabilidade superiores às das testemunhas, nos dois grupos de tegumento avaliados, em todas as épocas de semeadura.

Termos para indexação: Colletotrichum lindemuthianum, Fusarium oxysporum f. sp. phaseoli, Phaseolus vulgaris, Xanthomonas axonopodis pv. phaseoli, GGE biplot.

\section{Adaptability, stability and pathogen resistance in common bean genotypes}

\begin{abstract}
The objective of this work was to evaluate the resistance of bean genotypes to the main pathogens of the culture, and the adaptability and stability of these genotypes' grain yield. Twenty-six genotypes were evaluated for their resistance to Colletotrichum lindemuthianum, Fusarium oxysporum f. sp. phaseoli and Xanthomonas axonopodis pv. phaseoli, by inoculation, in laboratory, and in 19 trials the value for cultivation and use (VCU), in different locations of the state of São Paulo, Brazil, in "rainy", "dry", and "winter" seasons, during the growing years of 2011, 2012, and 2013. Eighteen genotypes were considered resistant, as follows: seven of them to $C$. lindemuthianum, seven to $F$. oxysporum $\mathrm{f}$. sp. phaseoli, and four to $X$. axonopodis pv. phaseoli. Resistance reaction to pathogens is associated with genotype stability. GGE biplot analyses made it possible to identify genotypes superior to the controls for adaptability and stability, in the two groups of integument evaluated in all sowing dates.

Index terms: Colletotrichum lindemuthianum, Fusarium oxysporum f. sp. phaseoli, Phaseolus vulgaris, Xanthomonas axonopodis pv. phaseoli, GGE biplot.
\end{abstract}

\section{Introdução}

O Brasil se destaca mundialmente entre os maiores produtores e consumidores de feijão, que é cultivado em todo o território nacional em diferentes condições e safras de cultivo (Lima et al., 2013). Assim, espera-se, quanto a essa cultura, alta influência da interação entre genótipos e ambientes (GxA) (Ramalho et al., 2012). Para reduzir os efeitos da interação GxA, é necessária a identificação de genótipos estáveis e adaptados às regiões para as quais estes serão recomendados.

$\mathrm{Na}$ avaliação de 16 genótipos de feijoeiro do tipo carioca, em 71 ensaios realizados nos estados de
Goiás, Mato Grosso, Mato Grosso do Sul, Tocantins, Paraná, Santa Catarina, São Paulo e no Distrito Federal, nos anos de 2003-2004, Pereira et al. (2009) observaram efeitos significativos quanto aos genótipos e ambientes, além da ocorrência de resposta diferencial dos genótipos aos ambientes. Os autores identificaram 'BRS Estilo' e CNFC 9518 como os genótipos mais produtivos, estáveis e adaptados, na média de todos os ambientes avaliados, e enfatizaram a importância da identificação dos genótipos com elevada produtividade, que se mostraram como os mais estáveis e adaptados para a adoção de novas cultivares. 
Silva et al. (2013b), ao determinar a adaptabilidade e estabilidade de 22 genótipos de feijoeiro no Estado de São Paulo, durante as safras das águas, seca e inverno, nos anos 2007, 2008 e 2009, observaram que os genótipos Gen C2-1-3, CNFC 10408, 'Juriti Claro' e LP 0472 foram os mais estáveis e adaptados para a região.

Diversos são os fatores que contribuem para a instabilidade de produção no feijoeiro; Zucareli et al. (2011) citam o uso inadequado de manejos culturais, sementes de baixa qualidade, incidência de doenças e pragas, além de problemas climáticos.

O crestamento bacteriano comum, causado por Xanthomonas axonopodis pv. phaseoli, é a principal bacteriose do feijoeiro no Brasil (Silva et al., 2013a). Entre as doenças fúngicas que mais afetam o feijão, Chiorato et al. (2015) citam a antracnose (Colletotrichum lindemuthianum), como uma das que mais acometem a parte aérea da planta, e a murcha de Fusarium (Fusarium oxysporum f. sp. phaseoli.).

Estes patógenos encontram-se amplamente disseminados nas principais regiões produtoras do Brasil, e a utilização de cultivares resistentes, juntamente com a adaptabilidade e estabilidade dos genótipos, é o método mais eficiente para a manutenção da produtividade da cultura (Silva et al., 2013a; Chiorato et al., 2015).

Diversos grupos de pesquisa buscam identificar genótipos resistentes às doenças que acometem a cultura do feijoeiro. Costa \& Rava (2003) selecionaram 152 famílias, em geração F6, resistentes (63\%) à mistura das raças 89 e 453 de C. lindemuthianum, entre as 243 avaliadas. Chiorato et al. (2015) estudaram 25 linhagens avançadas de feijoeiro, das quais 11 genótipos (44\%) mostraram reação de resistência à mistura das raças 31,65 e 81 de C. lindemuthianum. A resistência a múltiplas raças de F. oxysporum f. sp. phaseoli foi citada por Sala (2006), que avaliou 104 genótipos que apresentaram 33\% de resistência às raças $1,2,3$ e 4 do patógeno. Silva et al. (2009) avaliaram 56 cultivares de feijoeiro quanto à resistência ao crestamento bacteriano e encontraram $37 \%$ dos genótipos com resistência ao patógeno.

$\mathrm{O}$ objetivo deste trabalho foi avaliar a resistência de genótipos de feijoeiro aos principais patógenos da cultura, bem como a adaptabilidade e estabilidade de produção de grãos desses genótipos.

\section{Material e Métodos}

Utilizaram-se 22 linhagens avançadas de feijoeiro de tegumento carioca e preto, provenientes de diferentes instituições de pesquisa, com características agronômicas e de mercado desejáveis (Tabela 1). Como testemunhas, utilizaram-se as cultivares de tegumento carioca 'IAC Alvorada' e 'IPR 39', e as de tegumento preto 'IAC Diplomata' e 'IAC-Una' registradas e indicadas para o cultivo no Estado de São Paulo e descritas a seguir: 'IAC Alvorada', porte semiereto, elevada qualidade de grãos e suscetível à antracnose, à murcha de Fusarium e ao crestamento bacteriano (Chiorato et al., 2015); 'IPR 139', elevada qualidade de grãos e porte ereto, é moderadamente resistente ao crestamento bacteriano e suscetível à antracnose; 'IAC Diplomata', resistente à antracnose, moderadamente resistente à murcha de Fusarium e com elevada qualidade de grãos (Carbonell et al., 2008); e 'IAC-Una', resistente à antracnose e de porte ereto.

Para avaliar a adaptabilidade e estabilidade dos genótipos, utilizaram-se os dados de produtividade de 19 ensaios de VCU, realizados em diferentes municípios e safras (Tabela 2). Utilizou-se o delineamento experimental de blocos ao acaso, com três repetições, em que cada parcela constituiu-se de quatro linhas com 4,0 m de comprimento - que continham de 10 a 12 plantas por metro linear -, com $0,5 \mathrm{~m}$ entre linhas; as duas linhas centrais corresponderam à parcela útil $\left(4,0 \mathrm{~m}^{2}\right)$, conforme normas do Ministério da Agricultura, Pecuária e Abastecimento (Registro..., 2007).

Os dados de produtividade de grãos foram submetidos às análises de variância individuais e, após verificada a homogeneidade das variâncias residuais, realizou-se a análise de variância conjunta, por época de semeadura. As médias dos genótipos foram comparadas à da melhor testemunha correspondente a cada grupo de tegumento (Carioca ou Preto), pelo teste de Dunnett, a 5\% de probabilidade.

A avaliação da adaptabilidade e estabilidade foi realizada por meio do método GGE biplot (Yan et al., 2000). A análise gráfica foi modelada, levando-se em conta os dois primeiros componentes principais, de acordo com a equação,

$$
\mathrm{Y}_{\mathrm{ij}}-\overline{\mathrm{y}}_{\mathrm{j}}=\mathrm{y}_{1} \varepsilon_{\mathrm{i} 1}+\mathrm{y}_{2} \varepsilon_{\mathrm{i} 2} \rho_{\mathrm{j} 2}+\varepsilon_{\mathrm{ij}},
$$

em que: $Y_{i j}$ representa o rendimento médio da i-ésima população, no j-ésimo ambiente; $\bar{y}_{j}$ é a média geral 
das populações no ambiente $\mathrm{j} ; \mathrm{y}_{1} \varepsilon_{\mathrm{i} 1} \rho_{\mathrm{j} 1}$ é o primeiro componente principal (IPCA1); $\mathrm{y}_{2} \varepsilon_{\mathrm{i} 2} \rho_{\mathrm{j} 2}$ é o segundo componente principal (IPCA2), em que $\mathrm{y}_{1}$ e $\mathrm{y}_{2}$ são os autovalores associados ao IPCA1 e IPCA2 respectivamente; $\varepsilon_{1}$ e $\varepsilon_{2}$ são os escores do primeiro e segundo componente principal, respectivamente, da i-ésima população; $\rho_{\mathrm{j} 1}$ e $\rho_{\mathrm{j} 2}$ são os escores do primeiro e segundo componente principal, respectivamente, para o j-ésimo ambiente; e $\varepsilon_{\mathrm{ij}}$ é o erro do modelo associado à i-ésima população e ao j-ésimo ambiente (Yan et al., 2000). As análises foram realizadas por meio do software R (R Foundation for Statistical

Tabela 1. Genótipos de feijoeiro avaliados nos ensaios de VCU, para os anos agrícolas 2011, 2012 e 2013, no Estado de São Paulo.

\begin{tabular}{|c|c|c|}
\hline $\mathrm{Id}$ & Linhagem/cultivar & Instituição $^{(1)}$ \\
\hline & \multicolumn{2}{|c|}{ Genótipo tegumento carioca } \\
\hline 1 & IAC Alvorada ${ }^{(2)}$ & IAC \\
\hline 2 & IPR $139^{(2)}$ & Iapar \\
\hline 3 & CNFC 10729 & Embrapa \\
\hline 4 & CNFC 10762 & Embrapa \\
\hline 5 & CHC 01-175 & Epagri \\
\hline 6 & Gen C 4-7-8-1-2 & IAC \\
\hline 7 & Gen C 2-6-4-1-1 & IAC \\
\hline 8 & Gen C 4-7-2-2-1 & IAC \\
\hline 9 & IAC Milênio & IAC \\
\hline 10 & Gen C 5-3-6-1-1 & IAC \\
\hline 11 & Gen C2-6-6-2-1 & IAC \\
\hline 12 & LP 07-80 & Iapar \\
\hline 13 & LP 09-40 & Iapar \\
\hline 14 & BRSMG Madrepérola & Embrapa/Ufla/Epamig/UFV \\
\hline \multirow[t]{2}{*}{15} & MAII-2 & Ufla \\
\hline & \multicolumn{2}{|c|}{ Genótipos tegumento preto } \\
\hline 1 & IAC Diplomata $^{(2)}$ & IAC \\
\hline 2 & IAC-Una $^{(2)}$ & IAC \\
\hline 3 & CNFP 10794 & Embrapa \\
\hline 4 & CHP 98-66-20 & Epagri \\
\hline 5 & SM 1107 & Fepagro \\
\hline 6 & SM 1810 & Fepagro \\
\hline 7 & Gen PR 11-2-8-1-1 & IAC \\
\hline 8 & Gen PR 14-2-10-1-2 & IAC \\
\hline 9 & Gen PR 14-2-2-1-1 & IAC \\
\hline 10 & LP 09-192 & Iapar \\
\hline$\underline{11}$ & LP 08-90 & Iapar \\
\hline
\end{tabular}

${ }^{(1)}$ Embrapa, Empresa Brasileira de Pesquisa Agropecuária; Epagri, Empresa de Pesquisa Agropecuária e Extensão Rural de Santa Catarina, SC; IAC, Instituto Agronômico, SP; Iapar, Instituto Agronômico do Paraná, PR; Ufla, Universidade Federal de Lavras, MG; Fepagro, Fundação de Pesquisa Agropecuária, RS; UFV, Universidade Federal de Viçosa; Epamig, Empresa de Pesquisa Agropecuária de Minas Gerais. ${ }^{(2)}$ Cultivares utilizadas como testemunhas.
Computing, Viena, Áustria), tendo-se utilizado o pacote GGEBiplotGUI (Bernal \& Villardon, 2014).

$O$ ângulo entre os vetores de cada ambiente, determinado por meio da análise gráfica GGE biplot, indica a correlação entre eles, em que, quanto menor o ângulo, maior a associação (Yan \& Tinker, 2005).

Para avaliar a resistência dos 26 genótipos testados em ensaios de VCU, realizaram-se inoculações dos patógenos da antracnose, da murcha de Fusarium e do crestamento bacteriano comum, em ambientes controlados.

Para o início das avaliações, sementes dos genótipos e das testemunhas suscetíveis à antracnose (Rosinha G2 e Pérola) foram semeadas em bandejas de plástico, que continham vermiculita esterilizada, tendo-se realizado seis repetições.

$\mathrm{O}$ inóculo de $C$. lindemuthianum foi ajustado à concentração de $1 \times 10^{6}$ conídios $\mathrm{mL}^{-1}$, em câmara de Neubauer, em uma mistura com a mesma concentração das raças 31, 65 e 81, selecionadas com base na virulência e distribuição, mediante classificação de raças; estes isolados foram coletados respectivamente em Barretos, Botucatu e Itatiba, no Estado de São Paulo. Estes patógenos foram classificados de acordo com a

Tabela 2. Municípios onde foram conduzidos os ensaios de acordo com a safra.

\begin{tabular}{lcccc}
\hline Safra/Ano & Município & Latitude (S) & Longitude $(\mathrm{W})$ Altitude (m) \\
\hline \multirow{2}{*}{ Águas/2011 } & Capão Bonito & $24^{\circ} 00^{\prime}$ & $48^{\circ} 20^{\prime}$ & 702 \\
& Mococa & $21^{\circ} 28^{\prime}$ & $47^{\circ} 00^{\prime}$ & 645 \\
\hline \multirow{3}{*}{ Seca/2012 } & Avaré & $23^{\circ} 05^{\prime}$ & $48^{\circ} 55^{\prime}$ & 810 \\
& Mococa & $21^{\circ} 28^{\prime}$ & $47^{\circ} 00^{\prime}$ & 645 \\
& Taquarituba & $23^{\circ} 31^{\prime}$ & $49^{\circ} 14^{\prime}$ & 618 \\
\hline \multirow{5}{*}{ Inverno/2012(1) } & Colina & $20^{\circ} 42^{\prime}$ & $48^{\circ} 32^{\prime}$ & 595 \\
& Ribeirão Preto & $21^{\circ} 11^{\prime}$ & $47^{\circ} 48^{\prime}$ & 546 \\
& Votuporanga & $20^{\circ} 25^{\prime}$ & $49^{\circ} 58^{\prime}$ & 525 \\
\hline \multirow{5}{*}{ Águas/2012 } & Itararé & $24^{\circ} 06^{\prime}$ & $49^{\circ} 19^{\prime}$ & 740 \\
& Capão Bonito & $24^{\circ} 00^{\prime}$ & $48^{\circ} 20^{\prime}$ & 702 \\
& Taquarituba & $23^{\circ} 31^{\prime}$ & $49^{\circ} 14^{\prime}$ & 618 \\
\hline \multirow{5}{*}{ Seca/2013 } & Itararé & $24^{\circ} 00^{\prime}$ & $49^{\circ} 19^{\prime}$ & 702 \\
& Mococa & $21^{\circ} 28^{\prime}$ & $47^{\circ} 00^{\prime}$ & 645 \\
& Taquarituba & $23^{\circ} 31^{\prime}$ & $49^{\circ} 14^{\prime}$ & 618 \\
& Araras & $22^{\circ} 21^{\prime}$ & $47^{\circ} 23^{\prime}$ & 629 \\
\hline Inverno/2013 & Ribeirão Preto & $23^{\circ} 11^{\prime}$ & $47^{\circ} 48^{\prime}$ & 546 \\
& Votuporanga & $20^{\circ} 25^{\prime}$ & $49^{\circ} 58^{\prime}$ & 525 \\
\hline
\end{tabular}

${ }^{(1)}$ Experimentos irrigados. 
reação das doze variedades diferenciadoras, propostas na Primeira Reunião Latino Americana de Antracnose do Feijoeiro, realizada em Cali, Colômbia (Research..., 1990).

A inoculação foi realizada por meio de pulverização do inóculo à superfície aérea das plantas, em estádio $\mathrm{V}_{2}$ de desenvolvimento. Após a inoculação, as plantas foram transferidas para uma câmara com temperatura e umidade controladas $\left(20^{\circ} \mathrm{C}\right.$ e $95 \%$ de umidade relativa), onde permaneceram por 48 horas sob fotoperíodo de 12 horas. Em seguida, desligou-se o controle de umidade, e as plantas permaneceram por mais dez dias a $20^{\circ} \mathrm{C}$.

A avaliação foi realizada com base na severidade da doença, por meio da escala descrita em Pastor-Corrales (1991), com notas de 1 a 9, em que 1 representa planta completamente sem sintomas, e 9, necrose, desfolhamento e morte das plantas. Consideraram-se resistentes as plantas com notas de 1 a 3 , medianamente resistentes as de notas de 4 a 6 , e suscetíveis as de notas de 7 a 9.

Para a avaliação da resistência à murcha de Fusarium, sementes dos 26 genótipos e das testemunhas suscetíveis ao patógeno ('IAC Alvorada' e 'Rosinha G2') foram semeadas em bandejas de plástico, com vermiculita esterilizada, tendo-se utilizado 3 repetições para cada genótipo testado.

$\mathrm{O}$ inóculo de $F$. oxysporum foi ajustado para concentrações de $1 \times 10^{6}$ conídios $\mathrm{mL}^{-1}$ (macro e microconídios), em câmara de Neubauer, com uma mistura em mesma concentração das raças 1 (americana) e 2 (brasileira), coletados respectivamente em Angatuba e Capão Bonito, no Estado de São Paulo. As raças fisiológicas desses isolados foram identificadas pela metodologia proposta por Alves-Santos et al. (2002). A inoculação foi realizada pelo corte das raízes em um terço do comprimento, que foram imersas no inóculo durante o período de $15 \mathrm{~min}$; em seguida, as raízes foram transplantadas para vasos com $500 \mathrm{~g}$ de substrato (composto orgânico e terra na proporção de 1:1) acondicionados em casa de vegetação. A avaliação dos sintomas foi efetuada 30 dias após a inoculação, conforme escala de notas desenvolvida por Nascimento et al. (1995), em que 0 indica a ausência de sintomas (resistentes), e 4 plantas com nanismo, murchas ou mortas (suscetíveis). As notas intermediárias foram consideradas como medianamente resistentes.
Para a avaliação da resistência ao crestamento bacteriano comum ( $X$. axonopodis), utilizou-se o isolado 11280, coletado em Cosmópolis, SP, exemplar mais agressivo, proveniente do Centro de Fitossanidade do Instituto Agronômico. Sementes dos genótipos e da testemunha suscetível 'Rosinha G2' foram semeadas em vasos com $500 \mathrm{~g}$ de substrato (composto orgânico e terra na proporção de 1:1), tendo-se utilizado três repetições para cada genótipo avaliado.

O inóculo foi preparado pela adição de água destilada e esterilizada à superfície da colônia bacteriana e posterior raspagem com uma lâmina de vidro, com concentração ajustada a 108 UFC mL-1. A inoculação do patógeno foi realizada pela técnica de agulhas múltiplas, quando as folhas primárias do feijoeiro encontravam-se bem expandidas, em estádio $\mathrm{V}_{2}$ de desenvolvimento. $\mathrm{O}$ inóculo foi colocado em um recipiente com uma esponja e, com agulhas múltiplas, perfurou-se a folha primária com leve pressão entre a folha e a espuma, para possibilitar a entrada do inóculo através do ferimento (Pompeu \& Crowder, 1972). Após a inoculação, as plantas foram mantidas em câmara úmida, pelo período de 48 horas, com temperatura entre 25 e $28^{\circ} \mathrm{C}$ e, posteriormente, foram transferidas para a casa de vegetação. A avaliação dos sintomas ocorreu 10 dias após a inoculação, tendo-se utilizado escala de notas de 1 a 9 (Rava \& Sartorato, 1994). As notas de 1 a 2 indicaram plantas resistentes, de 3 a 6 medianamente resistentes, e de 7 a 9 suscetíveis ao patógeno.

\section{Resultados e Discussão}

Os coeficientes de variação da produtividade de grãos foram aceitáveis para todas as safras (Tabela 3). As maiores estimativas foram as da safra de inverno,

Tabela 3. Quadrados médios (QM) das análises de variância quanto à produtividade de grãos $\left(\mathrm{kg} \mathrm{ha}^{-1}\right)$ por safra (águas, seca e inverno), avaliada no Estado de São Paulo.

\begin{tabular}{lcccccc}
\hline Fonte de & \multicolumn{6}{c}{ Safra } \\
\cline { 2 - 7 } variação & GL & QM águas & GL & QM seca & GL & QM inverno \\
\hline Genótipo & 26 & $15,67^{* *}$ & 26 & $10,31^{*}$ & 26 & $4,97 * *$ \\
Ambiente & 4 & $524,63^{* *}$ & 6 & $880,59^{* *}$ & 6 & $300,7 * *$ \\
G x A & 104 & $6,33^{* *}$ & 156 & $6,77^{* *}$ & 156 & $2,52^{* *}$ \\
Resíduo & 260 & 2,16 & 364 & 1,48 & 364 & 1,35 \\
\hline Média & & 2.971 & & 2.831 & & 1.759 \\
CV $(\%)$ & 15,64 & & 13,6 & & 20,9 \\
\hline
\end{tabular}

*, **Significativo a 5 e $1 \%$ de probabilidade, respectivamente, pelo teste $\mathrm{F}$. $\mathrm{GL}$, grau de liberdade. CV, coeficiente de variação ambiental.

Pesq. agropec. bras., Brasília, v.50, n.10, p.912-922, out. 2015 DOI: $10.1590 / \mathrm{S} 0100-204 \mathrm{X} 2015001000007$ 
do ano de 2012, em que os experimentos foram atingidos por geadas mesmo na região recomendada para o cultivo nessa época.

Observaram-se diferenças significativas entre os tratamentos, em todas as safras avaliadas. A interação GxA foi significativa a $1 \%$, o que mostra a influência deste efeito em todas as safras avaliadas (Tabela 3 ). Isto indica que o comportamento dos genótipos foi diferenciado entre os ambientes avaliados.

$\mathrm{Na}$ safra das águas, observou-se que, entre os genótipos de tegumento preto, apenas a linhagem LP 09-192 (3.455 $\left.\mathrm{kg} \mathrm{ha}^{-1}\right)$ foi estatisticamente superior à testemunha 'IAC-Una' (2.609 $\left.\mathrm{kg} \mathrm{ha}^{-1}\right) \mathrm{e}$, quanto aos genótipos de tegumento carioca, nenhum diferiu

Tabela 4. Produtividade média dos genótipos por safra, avaliada no Estado de São Paulo.

\begin{tabular}{lcccc}
\hline Genótipo & Tegumento & \multicolumn{3}{c}{ Produtividade $\left(\mathrm{kg} \mathrm{ha}^{-1}\right)$} \\
\cline { 3 - 5 } & & Águas & Seca & Inverno \\
\hline IAC Alvorada & TC & $\underline{3.125}$ & $\underline{2.753}$ & $\underline{1.917}$ \\
Gen C 2-6-4-1-1 & $\mathrm{C}$ & 3.104 & 2.922 & 1.761 \\
Gen C 2-6-6-2-1 & $\mathrm{C}$ & 3.065 & 2.890 & 1.852 \\
Gen C 4-7-2-2-1 & $\mathrm{C}$ & 2.897 & 3.003 & 1.654 \\
IAC Milênio & $\mathrm{C}$ & 3.125 & 2.980 & 1.632 \\
Gen C 4-7-8-1-2 & $\mathrm{C}$ & 3.319 & 2.953 & 1.739 \\
Gen C 5-3-6-1-1 & $\mathrm{C}$ & 2.980 & 2.465 & 1.879 \\
CHC 01-175 & $\mathrm{C}$ & 3.208 & 2.997 & 2.042 \\
CHP 98-66-20 & $\mathrm{P}$ & 2.577 & 2.785 & 1.615 \\
CNFC 10729 & $\mathrm{C}$ & 3.180 & 2.509 & 1.784 \\
CNFC 10762 & $\mathrm{C}$ & 3.140 & 2.793 & 1.948 \\
CNFP 10794 & $\mathrm{P}$ & 3.016 & $3.323 *$ & 2.003 \\
IAC Diplomata & $\mathrm{TP}$ & 2.514 & 2.491 & 1.541 \\
IAC-Una & $\mathrm{TP}$ & $\underline{2.860}$ & $\underline{2.933}$ & 1.746 \\
IPR 139 & $\mathrm{TC}$ & 2.770 & 2.683 & 1.713 \\
LP 07-80 & $\mathrm{C}$ & 3.357 & 3.074 & 1.918 \\
LP 08-90 & $\mathrm{P}$ & 3.269 & 2.722 & 1.791 \\
LP 09-192 & $\mathrm{P}$ & $3.455 *$ & 2.892 & 1.850 \\
LP 09-40 & $\mathrm{C}$ & 3.604 & $3.217 *$ & 1.868 \\
BRSMG Madrepérola & $\mathrm{C}$ & 2.708 & 2.5 .81 & 1.693 \\
MAII-2 & $\mathrm{C}$ & 2.948 & 3.025 & 1.952 \\
Gen PR 11-2-8-1-1 & $\mathrm{P}$ & 2.728 & 2.666 & 1.688 \\
Gen PR 14-2-10-1-2 & $\mathrm{P}$ & 3.033 & 2.918 & 1.568 \\
Gen PR 14-2-2-1-1 & $\mathrm{P}$ & 2.768 & 2.932 & 1.459 \\
SM 1107 & $\mathrm{P}$ & 2.828 & 2.667 & 1.646 \\
SM 1810 & $\mathrm{P}$ & 2.150 & 2.798 & 1.514 \\
\hline Média & & 2.971 & 2.831 & 1.759 \\
CV (\%) & & 15,64 & 13,6 & 20,9 \\
\hline
\end{tabular}

*Diferença significativa, pelo teste de Dunnet, a $5 \%$ de probabilidade, em relação à melhor testemunha de tegumento carioca $(\mathrm{C})$ e preto $(\mathrm{P})$. TC e $\mathrm{TP}$, testemunha de tegumento carioca e preto, respectivamente. Valores sublinhados correspondem à melhor testemunha, para cada tipo de tegumento. estatisticamente da testemunha 'IAC Alvorada' (3.125 kg ha-1) (Tabela 4).

Na safra da seca, o genótipo LP 09-40 (3.217 $\left.\mathrm{kg} \mathrm{ha}^{-1}\right)$, de tegumento carioca, foi estatisticamente superior à testemunha 'IAC Alvorada' (2.753 $\left.\mathrm{kg} \mathrm{ha}^{-1}\right)$, pelo teste de Dunnet, a $5 \%$ de probabilidade. Entre os genótipos de tegumento preto, somente a linhagem CNFP 10794 $\left(3.323 \mathrm{~kg} \mathrm{ha}^{-1}\right)$ foi superior à testemunha 'IAC-Una' $\left(2.933 \mathrm{~kg} \mathrm{ha}^{-1}\right)$. Na safra de inverno, nenhum genótipo obteve desempenho estatisticamente superior às testemunhas.

Chiorato et al. (2015) avaliaram 21 genótipos de feijoeiro em ensaios de VCU, realizados nos anos agrícolas de 2009, 2010 e 2011, e não encontraram nenhuma linhagem estatisticamente superior às testemunhas 'IAC Alvorada', 'IAC-Una' e 'IAC Diplomata', em nenhuma das safras avaliadas.

Como se observou efeito significativo quanto à interação GxA, a indicação de um genótipo não deve ser realizada apenas pela média. De acordo com Yan \& Tinker (2005), nestes casos, por meio do método GGE biplot, é possível encontrar genótipos adaptados à determinada região, pelo agrupamento de ambientes em que os desempenhos dos genótipos foram similares, ou encontrar genótipos de adaptabilidade ampla e estável para o grupo de ambientes.

$\mathrm{Na}$ época das águas (Figura $1 \mathrm{~A}$ ), os ensaios realizados em Taquarituba e Itararé, no Estado de São Paulo, em 2012, foram correlacionados (ângulo menor que $90^{\circ}$ ). Estes municípios estão relativamente próximos, e foi possível formar um mega-ambiente em que os genótipos LP 08-90 e Gen C 4-7-8-1-2 se mostraram como os mais adaptados a esta região. Em contrapartida, o ensaio realizado em 2012, em Capão Bonito, SP, foi o mais distinto entre os avaliados, em que os genótipos LP 09-40, LP 09-192 e SM 1107 se mostraram como os mais adaptados.

$\mathrm{Na}$ safra de 2012, Mococa e Taquarituba foram agrupados; contudo, na safra de 2013, não foi possível o agrupamento destes ambientes. O mesmo fato pode ser observado na safra de inverno, em que os municípios de Votuporanga e Andradina, no Estado de São Paulo, foram agrupados em 2013, mas apresentaram baixa correlação em 2012. Estas divergências podem ter ocorrido em razão de diferenças climáticas entre os locais, o que fez com que o comportamento dos genótipos oscilasse entre os mega-ambientes formados (Yan \& Tinker, 2005; Tolessa \& Gela, 2014). 
Diante da impossibilidade de indicação de genótipos superiores com base em regiões específicas, Yan \& Tinker (2006) recomendam que a seleção desses genótipos seja feita com base em sua estabilidade e média, conforme Figuras 2, 3 e 4, para as safras das águas, seca e inverno, respectivamente. Nesses gráficos, os genótipos mais produtivos se encontram na parte superior da reta principal, no sentido da seta, enquanto a estabilidade do genótipo é observada pelo comprimento do vetor que, quanto menor, mais
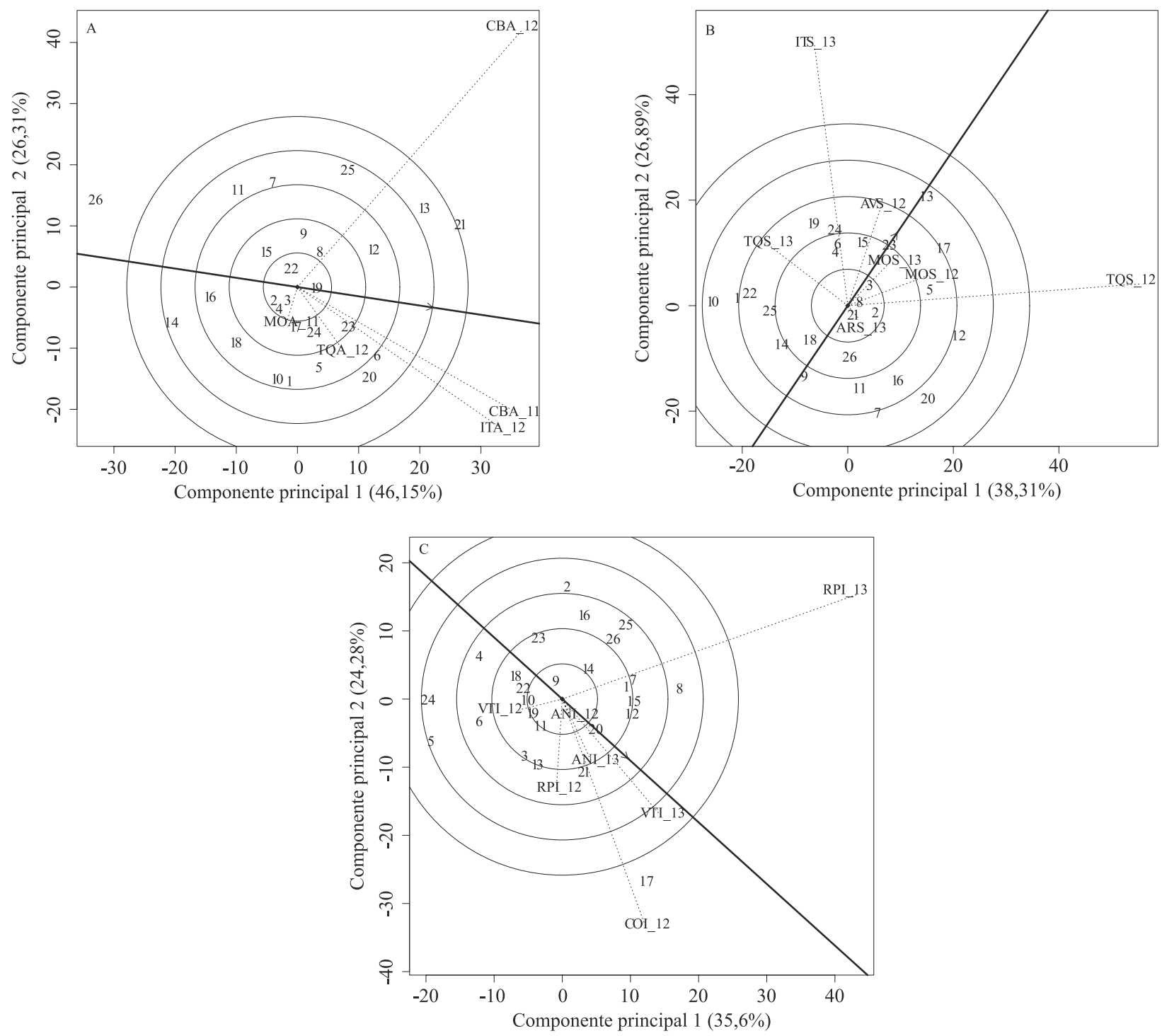

Figura 1. Análise GGE biplot da safra das águas (A), da seca (B) e do inverno (C), com os dois componentes principais de G + GA (AXIS 1 e AXIS 2) baseados na produtividade de grãos dos genótipos de feijoeiro: 1, IAC Alvorada; 2, Gen C 2-6-4-1-1; 3, Gen C 2-6-6-2-1; 4, Gen C 4-7-2-2-1; 5, IAC Milênio; 6, Gen C 4-7-8-1-2; 7, Gen C 5-3-6-1-1; 8, CHC 01-175; 9, CNFC 10729; 10, CNFC 10762; 11, IPR-139; 12, LP 07-80; 13, LP 09-40; 14, BRSMG Madrepérola; 15, MAII-2; 16, CHP 98-66-20; 17, CNFP 10794; 18, IAC Diplomata; 19, IAC-Una; 20, LP 08-90; 21, LP 09-192; 22, Gen PR 11-2-8-1-1; 23, Gen PR 14-2-10-1-2; 24, Gen PR 14-2-2-1-1; 25, SM 1107; e 26, SM 1810. A análise foi feita nos seguintes ambientes: CBA_11, Capão Bonito, 2011; MOA_11, Mococa, 2011; TQA_12, Taquarituba, 2012; ITA_12, Itararé, 2012; CBA_12, Capão Bonito, 2012; AVS_12, Avaré, 2012; COI_12, Colina, 2012; MOS_12, Mococa, 2012; TQS_12, Taquarituba, 2012; ITS_13, Itararé, 2013; TQS_13, Taquarituba, 2013; ARS_13, Araras, 2013; RPI_12, Ribeirão Preto, 2012; ANI_12, Andradina, 2012; VTI_12, Votuporanga, 2012; RPI_13, Ribeirão Preto, 2013; VTI_13, Votuporanga, 2013; e ANI_13, Andradina, 2013. 
estável é considerado o genótipo. Analisando-se a safra das águas, quanto aos genótipos de tegumento carioca (Figura $2 \mathrm{~A}$ ), observa-se que os quatro genótipos mais produtivos e superiores à testemunha 'IAC Alvorada' foram LP 09-40, LP 07-80, Gen C 4-7-8-1-2 e 'IAC Milênio', respectivamente. Embora, o genótipo LP 09-40 tenha sido o mais produtivo, quanto à estabilidade, os genótipos LP 07-80 e Gen C 4-7-8-1-2 foram mais estáveis, isto é, mostraram comportamento mais previsível para este grupo de ambientes avaliados.

Quanto aos genótipos de tegumento preto (Figura 2 B), observa-se que os genótipos mais produtivos e superiores às testemunhas foram LP 09-192, LP 08-90 e Gen PR 14-2-10-1-2, contudo, o genótipo LP 09-192 mostrou baixa estabilidade. Assim, destacou-se o genótipo Gen PR 14-2-10-1-2, que pode ser observado praticamente sobre a reta principal, que indica comportamento previsível para todos os ensaios.

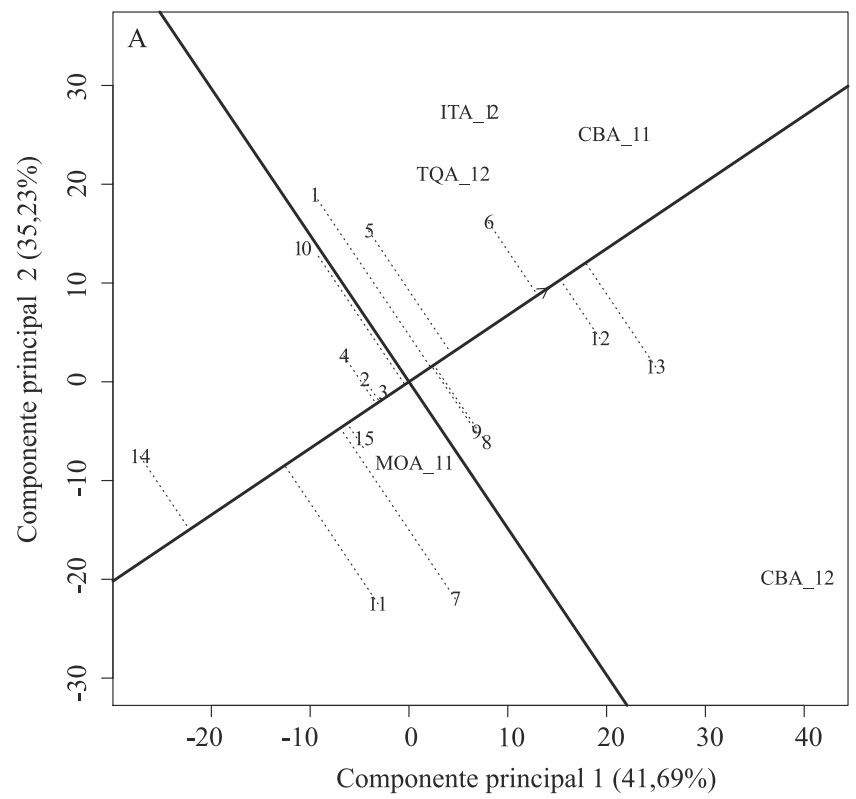

Para a época da seca, observa-se que LP 09-40 destacou-se entre os genótipos de tegumento carioca (Figura $3 \mathrm{~A}$ ) por ser estável e apresentar produtividade superior à da testemunha 'IAC Alvorada' (Tabela 4). Em seguida, os genótipos MAII-2, Gen C 4-7-8-1-2 e Gen C 4-7-2-2-1 também mostraram boa capacidade produtiva e estabilidade. Entre os genótipos de tegumento preto (Figura $3 \mathrm{~B}$ ), observa-se que o mais produtivo foi CNFP 10794, estatisticamente superior à testemunha 'IAC-Una' (Tabela 4). Entretanto, sua estabilidade foi menor do que a dos genótipos Gen PR 14-2-10-1-2 e LP 09-192. Assim, LP 09-40, Gen C 4-7-8-1-2 e MAII-2, de tegumento carioca, e CNFP 10794, de tegumento preto, podem ser indicados para cultivo na época da seca.

Analisando-se a safra de inverno, observa-se que, entre os genótipos de tegumento carioca (Figura 4 A), apenas dois genótipos foram superiores à testemunha 'IAC Alvorada', com destaque ao genótipo CHC 01-175, com alta produtividade e estabilidade.

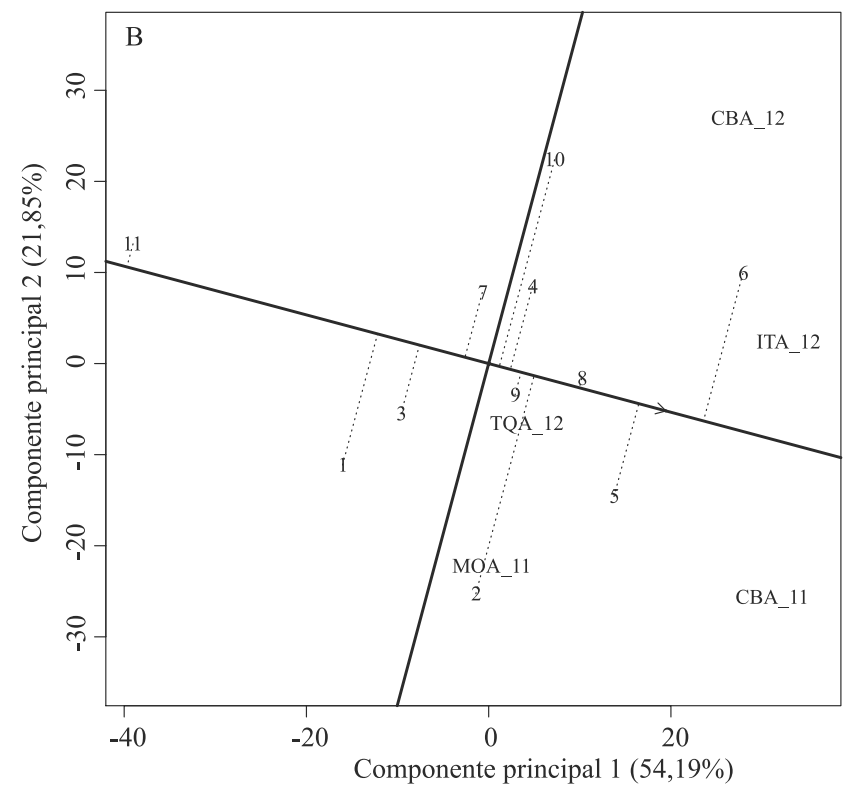

Figura 2. Análise GGE biplot para a safra das águas, no Estado de São Paulo, baseada na produtividade de 15 genótipos de feijoeiro de tegumento carioca (A) e 11 genótipos de feijoeiro de tegumento preto (B), avaliados em: CBA_11, Capão Bonito, 2011; MOA_11, Mococa, 2011; TQA_12, Taquarituba, 2012; ITA_12, Itararé, 2012; e CBA_12, Capão Bonito, 2012. Genótipos (A): 1, IAC Alvorada; 2, Gen C 2-6-4-1-1; 3, Gen C 2-6-6-2-1; 4, Gen C 4-7-2-2-1; 5, IAC Milênio; 6, Gen C 4-7-8-1-2; 7, Gen C 5-3-6-1-1; 8, CHC 01-175; 9, CNFC 10729; 10, CNFC 10762; 11, IPR 139; 12, LP 07-80; 13, LP 09-40; 14, BRSMG Madrepérola; 15, MAII-2. Genótipos (B): 1, CHP 98-66-20; 2, CNFP 10794; 3, IAC Diplomata; 4, IAC-Una; 5, LP 08-90; 6, LP 09-192; 7, Gen PR 11-2-8-1-1; 8, Gen PR 14-2-10-1-2; 9, Gen PR 14-2-2-1-1; 10, SM 1107; e 11, SM 1810. 

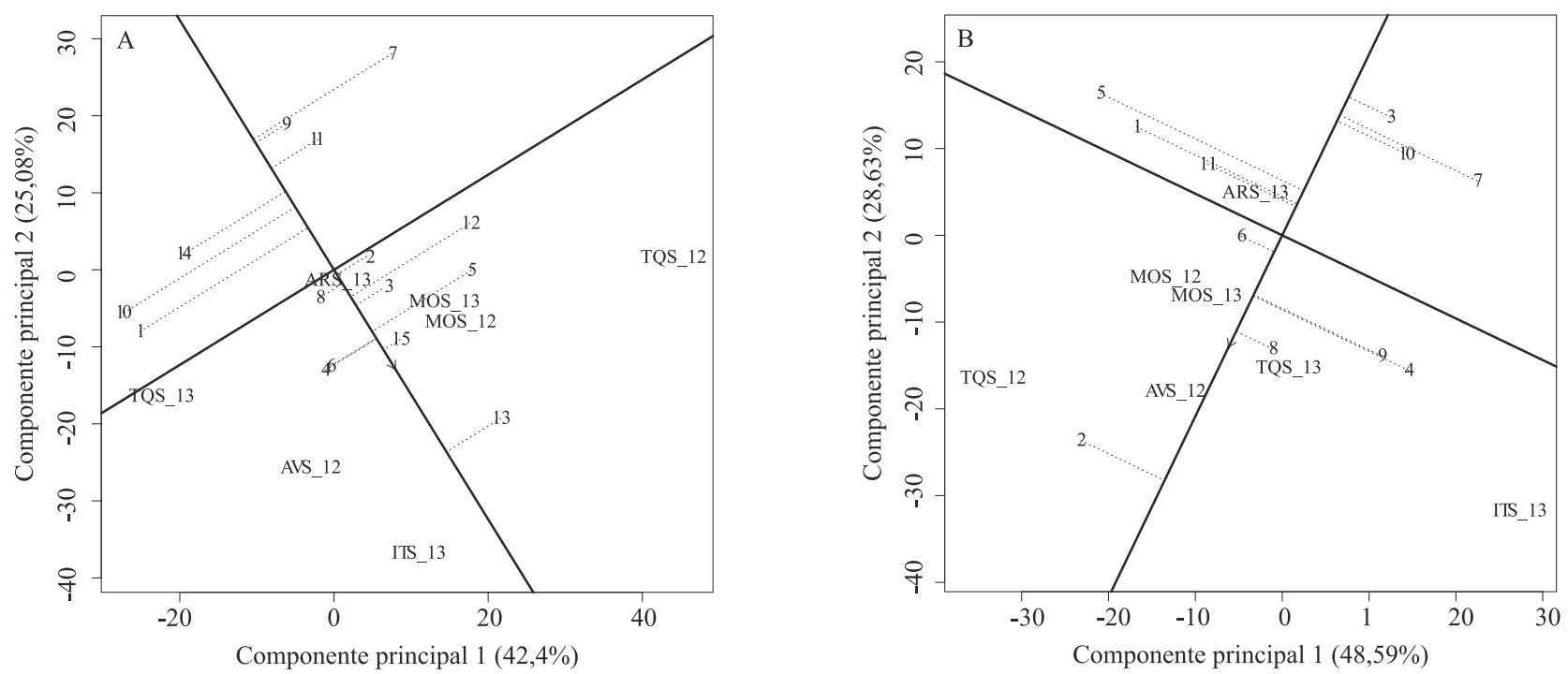

Figura 3. Análise GGE biplot da safra da seca no Estado de São Paulo, baseada na produtividade de 15 genótipos de feijoeiro de tegumento carioca (A) e 11 genótipos de feijoeiro de tegumento preto (B) avaliados em: MOS_12, Mococa, 2012; TQS_12, Taquarituba, 2012; AVS_12, Avaré, 2012; TQS_13, Taquarituba, 2013; MOS_13, Mococa, 2013; ,ARS_13, Araras, 2013; ITA_13, Itararé, 2013. Genótipos (A): 1, IAC Alvorada; 2, Gen C 2-6-4-1-1; 3, Gen C 2-6-6-2-1; 4, Gen C 4-7-2-2-1; 5, IAC Milênio; 6, Gen C 4-7-8-1-2; 7, Gen C 5-3-6-1-1; 8, CHC 01-175; 9, CNFC 10729; 10, CNFC 10762; 11, IPR 139; 12, LP 07-80; 13, LP 09-40; 14, BRSMG Madrepérola; 15, MAII-2. Genótipos (B): 1, CHP 98-66-20; 2, CNFP 10794; 3, IAC Diplomata; 4, IAC-Una; 5, LP 08-90; 6, LP 09-192; 7, Gen PR 11-2-8-1-1; 8, Gen PR 14-2-10-1-2; 9, Gen PR 14-2-2-1-1; 10, SM 1107; e 11, SM 1810.
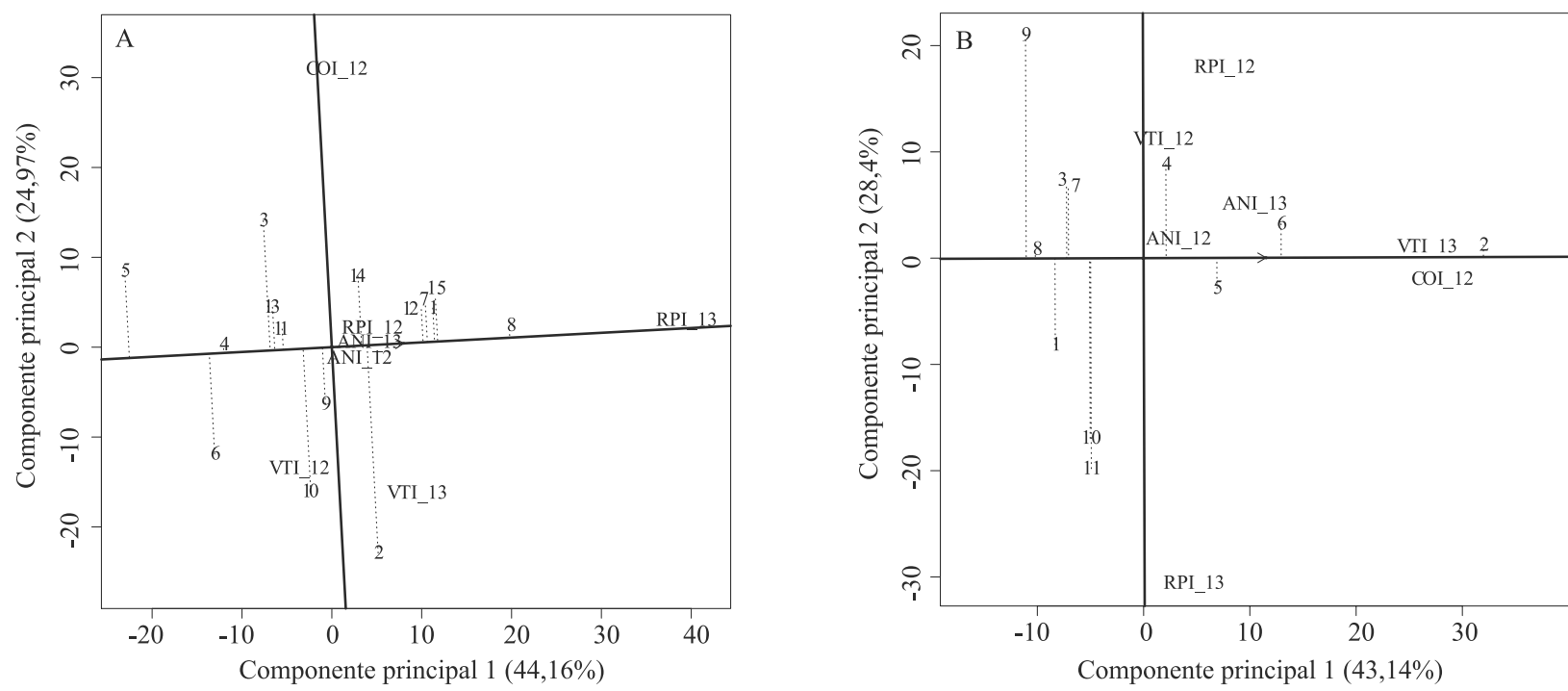

Figura 4. Análise GGE biplot da safra de inverno no Estado de São Paulo, baseada na produtividade de 15 genótipos de feijoeiro de tegumento carioca (A) e 11 genótipos de feijoeiro de tegumento preto (B), avaliados em: COI_12, Colina, 2012; RPI_12, Ribeirão Preto, 2012; ANI_12, Andradina, 2012; VTI_12, Votuporanga, 2012; RPI_13, Ribeirão Preto, 2013; ANI_13, Andradina, 2013; e, VTI_13, Votuporanga, 2013. Genótipos (A): 1, IAC Alvorada; 2, Gen C 2-6-4-1-1; 3, Gen C 2-6-6-2-1; 4, Gen C 4-7-2-2-1; 5, IAC Milênio; 6, Gen C 4-7-8-1-2; 7, Gen C 5-3-6-1-1; 8, CHC 01-175; 9, CNFC 10729; 10, CNFC 10762; 11, IPR139; 12, LP 07-80; 13, LP 09-40; 14, BRSMG Madrepérola; 15, MAII-2. Genótipos (B): 1, CHP 98-66-20; 2, CNFP 10794; 3, IAC Diplomata; 4, IAC-Una; 5, LP 08-90; 6, LP 09-192; 7, Gen PR 11-2-8-1-1; 8, Gen PR 14-2-10-1-2; 9, Gen PR 14-2-2-1-1; 10, SM 1107; e 11, SM 1810. 
Entre os genótipos de tegumento preto, destacaramse CNFP 10794, LP 09-192 e LP 08-90 (Figura 4 B) que, embora não tenham apresentado produtividade estatisticamente superior à da 'IAC-Una', mostraram estabilidade superior à desta testemunha e, assim, podem ser indicados como novas cultivares de feijoeiro.

A avaliação dos genótipos de feijoeiro quanto à resistência à antracnose resultou em sete genótipos resistentes, ou seja, 25\% do total avaliado (Tabela 5), dos quais três são genótipos de tegumento carioca CNFC 10762, LP 09-40 e MAII-2 -, e quatro são de tegumento preto - 'IAC Diplomata', 'IAC-Una', Gen PR 14-2-10-1-2 e Gen PR 14-2-2-1-1. Identificouse resistência moderada em $18,52 \%$ dos genótipos, quatro de tegumento carioca - 'IAC Milênio', Gen

Tabela 5. Avaliação da reação de resistência dos genótipos de feijoeiro aos patógenos Colletotrichum lindemuthianum, Fusarium oxysporum f. sp. phaseoli e Xanthomonas axonopodis pv. phaseoli, em casa de vegetação.

\begin{tabular}{lccc}
\hline Genótipo & \multicolumn{3}{c}{ Patógeno } \\
\cline { 2 - 4 } C. lindemuthianum & F. oxysporum X. axonopodis \\
\hline Gen C 2-6-4-1-1 & $\mathrm{S}$ & $\mathrm{S}$ & $\mathrm{S}$ \\
Gen C 2-6-6-2-1 & $\mathrm{S}$ & $\mathrm{S}$ & $\mathrm{S}$ \\
Gen C 4-7-2-2-1 & $\mathrm{S}$ & $\mathrm{S}$ & $\mathrm{S}$ \\
IAC Milênio & $\mathrm{S}$ & $\mathrm{S}$ & $\mathrm{S}$ \\
Gen C 4-7-8-1-2 & $\mathrm{MR}$ & $\mathrm{R}$ & $\mathrm{S}$ \\
Gen C 5-3-6-1-1 & $\mathrm{MR}$ & $\mathrm{MR}$ & $\mathrm{MR}$ \\
CHC 01-175 & $\mathrm{S}$ & $\mathrm{S}$ & $\mathrm{MR}$ \\
CHP 98-66-20 & $\mathrm{S}$ & $\mathrm{S}$ & $\mathrm{S}$ \\
CNFC 10729 & $\mathrm{S}$ & $\mathrm{MR}$ & $\mathrm{S}$ \\
CNFC 10762 & $\mathrm{S}$ & $\mathrm{R}$ & $\mathrm{S}$ \\
CNFP 10794 & $\mathrm{R}$ & $\mathrm{S}$ & $\mathrm{MR}$ \\
IAC Diplomata & $\mathrm{S}$ & $\mathrm{S}$ & $\mathrm{MR}$ \\
IAC-Una & $\mathrm{R}$ & $\mathrm{R}$ & $\mathrm{S}$ \\
IPR 139 & $\mathrm{R}$ & $\mathrm{S}$ & $\mathrm{S}$ \\
LP 07-80 & $\mathrm{S}$ & $\mathrm{S}$ & $\mathrm{S}$ \\
LP 08-90 & $\mathrm{MR}$ & $\mathrm{S}$ & $\mathrm{R}$ \\
LP 09-192 & $\mathrm{MR}$ & $\mathrm{R}$ & $\mathrm{R}$ \\
LP 09-40 & $\mathrm{S}$ & $\mathrm{MR}$ & $\mathrm{R}$ \\
BRSMG Madrepérola & $\mathrm{R}$ & $\mathrm{R}$ & $\mathrm{S}$ \\
MAII-2 & $\mathrm{R}$ & $\mathrm{S}$ & $\mathrm{S}$ \\
Gen PR 11-2-8-1-1 & $\mathrm{S}$ & $\mathrm{S}$ & $\mathrm{S}$ \\
Gen PR 14-2-10-1-2 & $\mathrm{R}$ & $\mathrm{S}$ & $\mathrm{S}$ \\
Gen PR 14-2-2-1-1 & $\mathrm{R}$ & $\mathrm{S}$ & $\mathrm{S}$ \\
SM 1107 & $\mathrm{MR}$ & $\mathrm{R}$ & $\mathrm{S}$ \\
SM 1810 & $\mathrm{S}$ & $\mathrm{S}$ \\
\hline R, & $\mathrm{R}$ \\
\hline
\end{tabular}

$\mathrm{R}$, resistente; MR, moderadamente resistente; e S, suscetível.
C 4-7-8-1-2, LP 07-80 e 'BRSMG Madrepérola' - e dois de tegumento preto, LP 08-90 e SM 1107.

Carneiro et al. (2012) citam a resistência de 'BRSMG Madrepérola' às raças 55, 65, 73, 81, 89,95 e 453 de C. lindemuthianum, entretanto, no presente trabalho, este genótipo foi identificado como medianamente resistente. Este resultado pode ser atribuído à utilização da raça 31 nas inoculações.

$\mathrm{Na}$ avaliação dos 26 genótipos quanto à susceptibilidade à murcha de Fusarium, sete $(25,92 \%)$ apresentaram reação de resistência, dos quais três são de tegumento carioca - 'IAC Milênio', CNFC 10729 e LP 09-40 -, e quatro são de tegumento preto 'IAC Diplomata', LP 08-90, Gen PR 14-2-2-1-1 e SM 1810 (Tabela 5). Sala (2006) avaliou 104 genótipos de feijão, dos quais 33\% apresentaram resistência às raças 1, 2, 3 e 4 da murcha de Fusarium, e relatou a dificuldade de encontrar cultivares resistentes ao patógeno, resultado semelhante ao obtido no presente estudo.

Em relação à $X$. axonopodis (Tabela 5), observa-se que apenas quatro genótipos foram identificados como resistentes, ou seja $14,81 \%$ do total avaliado. Desses genótipos, um apresenta tegumento carioca, LP 07-80, e três, tegumento preto - LP 08-90, LP 09-192 e SM 1810. No presente estudo, 'IAC-Una' apresentou reação de suscetibilidade ao patógeno; esse mesmo resultado foi indicado por e Silva et al. (2009).

Assim, foi possível encontrar genótipos mais adaptados e estáveis do que as testemunhas, além de genótipos com resistência aos patógenos avaliados. Observou-se que genótipos altamente produtivos e adaptados apresentaram baixa estabilidade na safra das águas e de inverno, como CNFP 10794 que, embora tenha apresentado as maiores médias de produção entre os genótipos de tegumento preto, apresentou baixa estabilidade em alguns ensaios.

\section{Conclusão}

1. A produtividade dos genótipos difere entre os ambientes e safras avaliados, o que indica influência da interação de genótipos por ambientes.

2. É possível identificar genótipos mais estáveis do que as testemunhas nos dois grupos de tegumento e safras avaliadas.

3. Genótipos com alta adaptabilidade e suscetíveis a doenças apresentam baixa estabilidade na safra 
das águas e do inverno, em condições favoráveis aos patógenos.

4. Observam-se genótipos com resistência aos patógenos avaliados, entretanto, nenhum genótipo foi resistente a todos os patógenos.

\section{Agradecimentos}

À Fundação de Apoio à Pesquisa do Estado de São Paulo (Fapesp), pelo apoio financeiro; ao Dr. Roberto Fritsche Neto e ao Sr. Ítalo Granato, do Departamento de Genética da Escola Superior de Agricultura Luiz e Queiroz (Esalq), pelo auxílio nas análises GGE biplot.

\section{Referências}

ALVES-SANTOS, F.M.; RAMOS, B.; GÁRCIA-SANCHEZ, M.A.; ESLAVA, A.P.; DÍAZ-MÍNGUEZ, J.M. A DNA-based procedure for in planta detection of Fusarium oxysporum f. sp. phaseoli. Phytopathology, v.92, p.237-244, 2002. DOI: 10.1094/ PHYTO.2002.92.3.237.

BERNAL, E.F.; VILLARDON, P.G. GGEBiplotGUI: interactive GGE biplots in R. 2014. Disponível em: <https://cran.r-project. org/web/packages/GGEBiplotGUI/index.html>. Acesso em: 10 out. 2014.

CARBONELL, S.A.M.; CHIORATO, A.F.; ITO, M.F.; PERINA, E.F.; GONÇALVES, J.G.R.; SOUZA, P.S. de; GALLO, P.B.; TICELLI, M.; COLOMBO, C.A.; AZEVEDO FILHO, J.A. de. IAC-Alvorada and IAC-Diplomata: new common bean cultivars. Crop Breeding and Applied Biotechnology, v.8, p.163-166, 2008. DOI: 10.12702/1984-7033.v08n02a10.

CARNEIRO, J.E. de S.; ABREU, A. de F.B.; RAMALHO, M.A.P.; PAULA JÚNIOR, T.J. de; DEL PELOSO, M.J.; MELO, L.C.; PEREIRA, H.S.; PEREIRA FILHO, I.A.; MARTINS, M.; VIEIRA, R.F.; MARTINS, F.A.D.; COELHO, M.A. de O.; CARNEIRO, P.C. de S.; MOREIRA, J.A.A.; SANTOS, J.B. dos; FARIA, L.C. de; COSTA, J.G.C. da; TEIXEIRA, H. BRSMG Madrepérola: common bean cultivar with late-darkening Carioca grain. Crop Breeding and Applied Biotechnology, v.12, p.281-284, 2012.

CHIORATO, A.F.; CARBONELL, S.A.M.; BOSETTI, F.; SASSERON, G.R.; LOPES, R.L.T.; AZEVEDO, C.V.G. Common bean genotypes for agronomic and market-related traits in VCU trials. Scientia Agricola, v.72, p.34-40, 2015. DOI: 10.1590/0103-9016-2013-0172.

COSTA, J.G.C. da; RAVA, C.A. Linhagens de feijoeiro comum com fenótipos agronômicos favoráveis e resistência ao crestamento bacteriano comum e antracnose. Ciência e Agrotecnologia, v.27, p.1176-1182, 2003. DOI: 10.1590/S1413-70542003000500029.

LIMA, L.K. de; RAMALHO, M.A.P.; FERREIRA, R.A.D.C.; ABREU, Â. de F.B. Repeatability of adaptability and stability parameters of common bean in unpredictable environments. Pesquisa Agropecuária Brasileira, v.48, p.1254-1259, 2013. DOI: 10.1590/S0100-204X2013000900009.

NASCIMENTO, S.R.C.; KUROZAWA, C.; MARINGONI, A.C. Avaliação de raças fisiológicas de Fusarium oxysporum f. sp. phaseoli. Fitopatologia Brasileira, v.20, p.214-217, 1995.

PASTOR-CORRALES, M.A. Estandarización de variedades diferenciales y de designación de razas de Colletotrichum lindemuthianum. Phytopathology, v.81, p.694, 1991.

PEREIRA, H.S.; MELO, L.C.; DEL PELOSO, M.J.; FARIA, L.C. de; COSTA, J.G.C. da; DÍAZ, J.L.C.; RAVA, C.A.; WENDLAND, A. Comparação de métodos de análise de adaptabilidade e estabilidade fenotípica em feijoeiro-comum. Pesquisa Agropecuária Brasileira, v.44, p.374-383, 2009. DOI: 10.1590/ S0100-204X2009000400007.

POMPEU, A.S.; CROWDER, L.V. Inheritance of resistance of Phaseolus vulgaris L. (dry bean) to Xanthomonas phaseoli Dows. Ciência e Cultura, v.24, p.1055-1063, 1972.

RAMALHO, M.A.P.; ABREU A. de F.B.; SANTOS J.B. dos; NUNES, J.A.R. Aplicações da genética quantitativa no melhoramento de plantas autógamas. Lavras: Ed. da Ufla, 2012. $522 \mathrm{p}$.

RAVA, C.A.; SARTORATO, A. Crestamento bacteriano comum. In: SARTORATO, A.; RAVA, C.A. (Ed.). Principais doenças do feijoeiro comum e seu controle. Brasília: EMBRAPA-SPI, 1994. p.217-242. (EMBRAPA-CNPAF. Documentos, 50).

REGISTRO Nacional de Cultivares RNC: orientações e informações técnicas. Brasília: Ministério da Agricultura, Pecuária e Abastecimento, 2007. Disponível em: <http://www. agricultura.gov.br/arq_editor/file/vegetal/Sementes_e_mudas/ Registro_Nacional_de_Cultivares.pdf $>$. Acesso em: 10 out. 2014.

RESEARCH constraints provisionally identified by CIAT [(Centro Internacional de Agricultura Tropical)]. In: WORKSHOP ON ADVANCED PHASEOLUS BEAN RESEARCH NETWORK, 1990, Cali. [Documents] Cali: CIAT, 1990. 30p.

SALA, G.M.; ITO, M.F.; CARBONELL, S.A.M. Reação de genotipos de feijoeiro comum a quatro raças de Fusarium oxysporum f. sp. phaseoli. Summa Phytopathologica, v.32, p.286-287, 2006. DOI: 10.1590/S0100-54052006000300014.

SILVA, A. da; SANTOS, I. dos; BALBINOT, A.L.; MATEI, G.; OLIVEIRA, P.H. de. Reação de genótipos de feijão ao crestamento bacteriano comum, avaliado por dois métodos de inoculação. Ciência e Agrotecnologia, v.33, p.2019-2024, 2009. DOI: 10.1590/S1413-70542009000700054.

SILVA, F.C.; SOUZA, R.M. de; ZACARONI, A.B.; LELIS, F.M.V.; FIGUEIRA, A. dos R. Otimização da técnica de PCR para a detecção de Xanthomonas axonopodis pv. phaseoli em sementes de feijão. Summa Phytopathologica, v.39, p.45-50, 2013a. DOI: 10.1590/S0100-54052013000100008.

SILVA, G.A.P.; CHIORATO, A.F.; GONÇALVES, J.G.R.; PERINA, E.F.; CARBONELL, S.A.M. Análise da adaptabilidade e estabilidade de produção em ensaios regionais de feijoeiro para o 
Estado de São Paulo. Ceres, v.60, p.59-65, 2013b. DOI: 10.1590/ S0034-737X2013000100009.

TOLESSA, T.T.; GELA, T.S. Sites regression GGE biplot analysis of haricot bean (Phaseolus vulgaris L.) genotypes in three contrasting environments. World Journal of Agricultural Research, v.2, p.228-236, 2014. DOI: 10.12691/ wjar-2-5-5.

YAN, W.; HUNT, L.A.; SHENG, Q.; SZLAVNICS, Z. Cultivar evaluation and mega-environment investigation based on the GGE biplot. Crop Science, v.40, p.597-605, 2000. DOI: 10.2135/ cropsci2000.403597x.
YAN, W.; TINKER, N.A. Biplot analysis of multi-environment trial data: principles and applications. Canadian Journal of Plant Science, v.86, p.623-645, 2006. DOI: 10.4141/P05-169.

YAN, W.; TINKER, N.A. An integrated biplot analysis system for displaying, interpreting, and exploring genotype $\times$ environment interaction. Crop Science, v.45, p.1004-1016, 2005. DOI: 10.2135/ cropsci2004.0076.

ZUCARELI, C.; PRANDO, A.M.; RAMOS JUNIOR, E.U.; NAKAGAWA, J. Fósforo na produtividade e qualidade de sementes de feijão Carioca Precoce cultivado no período das águas. Revista Ciência Agronômica, v.42, p.32-38, 2011. DOI: 10.1590/S1806-66902011000100005.

Recebido em 24 de novembro de 2014 e aprovado em 23 de julho de 2015 